\title{
Comparison of ergonomic risk assessment results from Quick Exposure Check and Rapid Entire Body Assessment in an anodizing industry of Tehran, Iran
}

\author{
Nadri H, MSc ${ }^{1}$, Fasih F, MSc ${ }^{1}$, Nadri F, $\mathrm{MSc}^{2 *}$, Nadri A, BSc ${ }^{3}$ \\ 1- MSc Student, Dept., of Occupational Health, School of Public Health, Shahid Beheshti University of Medical Sciences, Tehran, Iran. \\ 2- PhD Student, Dept., of Occupational Health, School of Medical Sciences, Tarbiat Modares University, Tehran, Iran. 3- BSc Student, \\ Dept., of Occupational Health, School of Public Health, Hmadan University of Medical Sciences, Hamadan, Iran.
}

Background: The aim of this paper was the comparison of ergonomic risk assessment results (final score and action levels) for the entire body as determined using Quick Exposure Check (QEC) and Rapid Entire Body Assessment (REBA).

Materials and Methods: This was a cross-sectional study in which all 82 workers engaged in various processes with different activities in an anodizing and aluminum profiles producing industry in Tehran, Iran, were studied. The REBA and QEC ergonomic risk assessment techniques and Nordic Musculoskeletal Questionnaire (NMQ) were used in order to assess the correlation between results of the two methods and evaluate the correlation between the prevalence of musculoskeletal disorders and the results of these two methods.

Results: Studied postures, using QEC and REBA assessment methods, acquired the risk levels, respectively, of low risk $=10.9 \%$, moderate risk $=25.5 \%$, and high/very high risk $=63.6 \%$ in $\mathrm{QEC}$. They obtained the risk levels of low risk $=56.3 \%$, moderate risk $=40 \%$, and high/very high risk $=12.7 \%$, respectively, in REBA. The kappa (0.12) and gamma scores (0.51) showed no agreement between the outputs of the two tools. No significant correlation $(\mathrm{P}>0.05)$ was found between final scores of these two methods and prevalence of musculoskeletal disorders.

Conclusions: These results indicate that the risk assessment outcomes of these two ergonomic assessment tools for the entire body do not agree. Thus, there is no possibility of applying them interchangeably for postural risk assessment, at least not in this industry.

Keywords: Musculoskeletal Diseases, Risk Assessment, Industry.

\section{Introduction}

Concurrent with industrial growth, human health threatening disease patterns have changed. From the middle of the twentieth century, a meaningful amount of infectious diseases have been witnessed; however, an incredible increase has also been observed in diseases associated with industrial life such as accidents, cardiovascular diseases, and musculoskeletal disorders $(1,2)$. Results of various studies indicate that in spite of the increasing mechanization and automation processes, yet a major part of work activities are manually performed by humans $(3,4)$. Moreover, the prevalence of musculoskeletal disorders, as the main reason for wasting time,_worker absenteeism, increased costs (5), productivity reduction, workforce injury and disability, and economic losses $(6,7)$, is related to the work environment. Thus, musculoskeletal disorders are considered as the principal occupational health problem throughout the world (8), and the most common cause of occupational injury and disability in industrialized and developing countries (9). Work-related musculoskeletal disorders (WMSDs) include disorders of muscles,

\footnotetext{
* Corresponding author: Farshad Nadri, PhD Student, Dept., of Occupational Health, School of Medical Sciences, Tarbiat Modares University, Tehran, Iran. Email: nadrifarshad64@gmail.com
} 
tendons, tendon sheaths, peripheral nerves, joints, bones, ligaments, and blood vessels. WMSDs usually occur as a result of repetitive stress over time or an immediate or acute trauma (such as slip and fall). Moreover, they have symptoms such as discomfort, pain, fatigue, swelling, stiffness, numbness, and tingling, that do not indicate existence of musculoskeletal disorders but the risk of these disorders in the light of untreated conditions $(10,11)$. These disorders begin with fatigue and pain, and result in restriction of limb movement, and finally, muscle loss (12). Musculoskeletal disorders, constitute nearly half of all work-related diseases $(10,11)$. Bernard et al, have shown that manual load handling, repetitive actions, high-speed work, inadequate rest time, static work, vibration, abnormal condition of the body, and adverse circumstances which could be resolved or minimized are the major risk factors for WMSDs (13).

Many tools are available for the assessment of risk factors for these disorders. Rapid Entire Body Assessment (REBA) and Quick Exposure Check (QEC) are methods for evaluation of ergonomic risk factors related to upper and lower extremities of the musculoskeletal system (entire body). In different studies, these methods have been used to evaluate occupations in the construction industry $(14,15)$, sugar industry (16), and in hospitals (17).

Each ergonomic risk assessment method has a classification of body posture, ultimately, their risk levels can be varried due to the differences in the process of information and basic of any method. Although REBA and QEC methods are used to evaluate the entire body, each of them studied different factors. For example, REBA can study posture of trunk, neck, and legs (in combination with force/load score) and upper arms, lower arms, and wrists (in combination with coupling score), however, the QEC can study posture of back, shoulder/upper arm, wrist/hand, and neck combined with the score of task duration, weight handled, hand force exertion, vibration exposure, and visual task demands which are obtained from the workers (1822).
Only the study by Motamedzade et al. was found to compare the risk assessment outputs of QEC and REBA (21). They found a significant correlation between results $(r=0.731$ for final scores and $r=$ 0.893 for action levels), and even reported the possibility of interchangeable application of the two methods (23). Nevertheless, we believe that in ergonomic risk assessment or postural assessment of occupations using these two methods, according to mentioned reasons, achieving the same results (significant correlation) when studying the same job may not be possible and interchangeable application of these two methods may be not reasonable.

The purpose of this study was to compare ergonomic risk assessment results predicted by QEC and REBA methods in an anodizing industry in Tehran, Iran.

\section{Materials and Methods}

This was a cross-sectional study performed in an anodizing and aluminum profiles producing industry in Tehran in 2013. We studied all workers $(n=82)$ engaged in various processes in this industry. The different activities of the workers were recorded using video and photography. Obtained data were analyzed in order to compare ergonomic risk assessment results of QEC and REBA (final score and action levels) and evaluate the correlation between the prevalence of musculoskeletal disorders and results of these two methods. To achieve this goal, working postures in all current jobs in this industry were assessed using QEC and REBA. Moreover, in order to assess musculoskeletal disorders, the Nordic Musculoskeletal Questionnaire (NMQ) was used.

Ergonomics risk assessment: The most important issue in the postural assessment of occupations using ergonomic methods is determining desired posture in order to assess and inspect. To achieve this purpose, we require task analysis of all professions. In order to perform task analysis in this study, the Kochran et al. method (24) was used; all jobs were divided into their tasks and the duration of each task was measured accordingly. By considering the time assigned to each task and postural assessment of all 
tasks, the task that was performed with the worst posture was selected in order to compare ergonomic risk assessment results of QEC and REBA.

Rapid Entire Body Assessment (REBA): This method was presented by Highnet and Mc Atamney (25) and is based on the principle of the Rapid Upper Limb Assessment (RULA) method. This method is suitable for assessing tasks in which individuals have dynamic and static body status. The validity and stability of this method has been approved by Saremi et al. among Shahed University dentists in Iran (26). In this method, to analyze the various body parts, they were divided into two groups (A and B). In group A, postures of body parts such as trunk, neck, and legs are checked, and the force/load score is add to the group A score. In group B, upper arms, lower arms, and wrists are scored and coupling score is added to this score. Thus, these body parts are scored based on their positions and degree of deviation from normal posture. Then, by combining $\mathrm{A}$ and $\mathrm{B}$ scores, the $\mathrm{C}$ score is obtained. Subsequently, the activity score is added to $\mathrm{C}$ score and the total REBA score is obtained. The final score of REBA is divided into 5 levels of risk from 0 to 4 that correspond to negligible, low, moderate, high and very high, respectively.

Quick Exposure Check (QEC): This method was presented by $\mathrm{Li}$ and Buckle in 1998 (27), and extended by David et al. in 2003 (28). In this observational method, postures and movements of body parts, including back, shoulder/upper arm, wrist/hand, and neck, are assessed. Furthermore, information is obtained about work conditions such as task duration, maximum weight handled, hand force exertion, vibration exposure, and task visual demands from the workers. Therefore, the total QEC score for each task is based on a combination of scores of each body part assessed by the observer and worker. Finally, in order to determine risk level of tasks, this total score is divided by the maximum possible score (i.e., 176 for manual material handling tasks and 162 for others). There are 4 categories for risk levels; low scores/low risk $(<40 \%)$, moderate risk $(41 \%-51 \%)$, high risk $(51 \%$ $70 \%)$, and very high risk (>70\%). These categories represent satisfactory level, more investigation is needed and interventions may be required, investigation and interventions are required promptly, and investigation and interventions are urgently required, respectively. The assessment of each task can normally be completed within about 10 minutes.

To allow the comparison of these two methods' outputs, in REBA, negligible and low, and high and very high categories were combined to form 2 categories (low and high, respectively). In addition, in QEC, high and very high categories were combined to form 1 category (High) (Table 1).

Table 1: Risk categories used to compare output scores of the QEC and REBA
methods for assessing WMSDs risk
\begin{tabular}{cccc}
\hline Methods & Low & Moderate & High \\
\hline REBA & 1 & $2-7$ & $8-15$ \\
QEC & $<40 \%$ & $\geq 40 \%-<70 \%$ & $\geq 70 \%$ \\
\hline
\end{tabular}

QEC: Quick Exposure Check, REBA: Rapid Entire Body Assessment, WMSDs: Work-related musculoskeletal disorders

Data analysis was performed using SPSS software (version 16, SPSS Inc., Chicago, IL, USA). We used descriptive statistics to describe the results of the REBA and QEC methods (final score and action level). For the assessment of agreement and monotonicity between the results of these methods, the kappa and gamma scores were used, respectively. For the assessment of correlation between the final scores of these two methods and prevalence of musculoskeletal disorders, one-way ANOVA was used. 
Table 2: Percentage of action levels of postures analyzed by QEC and REBA methods

\begin{tabular}{ccc}
\hline Action levels & REBA Action Level & QEC Action Level \\
\hline Low risk & 56.3 & 10.9 \\
\hline Moderate risk & 30.9 & 25.5 \\
\hline High risk & 12.7 & 63.7 \\
\hline & Quartiles & \\
\hline $25^{\text {th }}$ & 2 & 3 \\
\hline $50^{\text {th }}$ & 2 & 3 \\
\hline $75^{\text {th }}$ & 3 &
\end{tabular}

QEC: Quick Exposure Check, REBA: Rapid Entire Body Assessment

\section{Results}

Based on the results presented in table 2, in REBA assessment, low risk level $(56.3 \%)$ has the greatest portion, while in QEC assessment, the high risk level $(63.7 \%)$ has the greatest portion in analyzed postures. According to table 3, the average final scores of REBA and QEC methods were 7.44 and
99.75, respectively. As shown in table 3, in REBA assessment, $50 \%$ of analyzed postures have final scores of less than 7 and $25 \%$ of analyzed postures have final scores of less than 5.25. Moreover, results indicated that $50 \%$ of postures analyzed by QEC have a final score of less than 98 and $25 \%$ of analyzed postures have a final score of less than 80 .

Table 3: Mean and quartiles results of final scores from REBA and QEC

\begin{tabular}{|c|c|c|c|c|c|}
\hline \multicolumn{3}{|c|}{ REBA final score } & \multicolumn{3}{|c|}{ QEC final score } \\
\hline \multirow{2}{*}{ Mean } & \multicolumn{2}{|c|}{ 95\% Confidence Interval } & \multirow{2}{*}{ Mean } & \multicolumn{2}{|c|}{ 95\% Confidence Interva } \\
\hline & Lower & Upper & & Lower & Upper \\
\hline 7.44 & 6.77 & 8.11 & 99.75 & 92.78 & 106.71 \\
\hline \multicolumn{6}{|c|}{ Quartiles } \\
\hline $25^{\text {th }}$ & & & & 80.00 & \\
\hline $50^{\text {th }}$ & & & & 98.00 & \\
\hline $75^{\text {th }}$ & & & & 121.50 & \\
\hline
\end{tabular}

QEC: Quick Exposure Check, REBA: Rapid Entire Body Assessment

Assessment of correlation between the results of these two methods showed the kappa score was equal to 0.12 , which indicates no agreement between the outputs of these two tools. Furthermore, a weak monotonicity with a gamma score equal to 0.51 was found between these results. One-way ANOVA results showed no significant difference in assessment of correlation between the final scores of these two methods and prevalence of musculoskeletal disorders in 9 body parts (frequency: 0-9) by workers (Table 4).

\section{Discussion}

As shown in table 2, of the workstations analyzed using REBA, $56.3 \%$ and $12.7 \%$ were at low risk (change in posture may be necessary) and high risk (requires immediate change), respectively. Furthermore, $75 \%$ of analyzed postures have an action level equal to 2 or lower (or final scores of less than 9.75).

However, $10.9 \%$ and $63.7 \%$ of workstations analyzed using QEC were categorized as low risk (indicating further investigation) and high risk 
(indicating immediate need for investigation and intervention), respectively. In addition, $25 \%$ of analyzed postures have an action level equal to 2 or lower (or final scores of less than 80).

Table 4: One-way ANOVA results for REBA and QEC final scores in workers with 0-8 reported WMSDs in various body parts

\begin{tabular}{ccc}
\hline $\begin{array}{c}\text { Frequency of WMSDs } \\
\text { reported }\end{array}$ & $\begin{array}{c}\text { REBA final score } \\
\text { (Mean) }\end{array}$ & $\begin{array}{c}\text { QEC final score } \\
\text { (Mean) }\end{array}$ \\
\hline 0 & 7.14 & 92.14 \\
\hline 1 & 7 & 95.77 \\
\hline 2 & 8 & 114.36 \\
\hline 3 & 7.87 & 94.5 \\
\hline 4 & 6.8 & 105.2 \\
\hline 5 & 8.33 & 94 \\
\hline 6 & 8 & 112 \\
\hline 7 & 7.5 & 75 \\
\hline 8 & 6.5 & 119 \\
\hline$P$ & 0.355 & 0.974 \\
\hline
\end{tabular}

QEC: Quick Exposure Check, REBA: Rapid Entire Body Assessment, WMSDs: Work-related musculoskeletal disorders

Our findings are in agreement with that of the study by Zare et al. that categorized $14.3 \%$ and $56 \%$ of workers using QEC as low and high risk level, respectively (26). Moreover, our results are not in accordance with that of the study by Qutubuddin et al. that categorized $18.18 \%$ and $55.46 \%$ of workers using REBA as low and high risk level, respectively (29). Chiasson et al. (30) and Qutubuddin et al. (31) have reported the percentage of assessed workstations that were classified in the high risk category using REBA as $70 \%$ and $23.6 \%$, and using QEC as $35 \%$ and $34.21 \%$, respectively. At first glance, the smallest and largest proportions of the high risk category in our study were assigned to REBA and QEC, respectively. These amounts differ from the results of the abovementioned studies.

One-way ANOVA results, as illustrated in table 4, showed no significant difference in REBA and QEC final scores between workers without and with 1 to 8 musculoskeletal disorders in body parts. Since such relation has not been investigated in other studies, we could not have a comparative assessment. The lack of relation between and consistency of REBA and QEC final scores in workers with 0-8 reported WMSDs in various body parts can be attributed to adverse signs of WMSDs in studied workers.
Although risk factors, such as manual load handling, repetitive actions, static work, and adverse postural condition of the body while working, are combined with the final scores of these two methods, it is not unexpected to observe a rise in the prevalence of WMSDs along with an increase in final scores. However, it is not expected to find a complete correlation between final score of ergonomic risk analysis tools and WMSDs prevalence. In other words, prediction of WMSDs using a questionnaire based on workers' perception would not be very reliable.

The QEC method has the ability to take into account work characteristics like posture, weight/effort force applied, frequency, duration, movements, psychosocial factors, and worker's perception/opinion, which may result in bias due to differences in perception. This results in a more comprehensive and detailed analysis of workers/workstations. However, the REBA method only takes into account posture and weight/effort force applied in postural analysis. Moreover, this resulted in the QEC method obtaining a greater portion of the high risk category in assessing risk of MSDs. In other words, REBA was a Comprehensive 
method for assessing risk factors associated with musculoskeletal disorders.

The key finding of this study is that there is no agreement between results of the two methods. The small Kappa coefficient (0.12) showed little agreement between the results of REBA and QEC methods. This is supported by the lack of monotonicity (with a gamma score of 0.51 ) that is a measure which indicates how well two variables correlate. Motamedzade et al. compared the outputs of QEC and REBA methods (23). The results showed that regardless of task type, these methods' estimations for posture-related risk were similar (21). The correlation coefficients for QEC and REBA outputs, including final scores $(r=0.73)$ and action levels $(r=0.89)$, were computed, and a considerable agreement was found between the outputs of these two methods. In addition, Chiasson et al. (30) found a significant correlation $(\mathrm{r}=0.35, \mathrm{P}$ $<0.001)$ in the comparison of QEC and REBA methods' results. Furthermore, the percentage of agreement between these risk assessment methods for workstations identified as high category was reported as equal to $46 \%$. In general, our study results were not in agreement with the abovementioned studies, and therefore, there is no possibility of the interchangeable application of these methods, at least in the workplaces like this study.

However, in a study entitled comparison of ergonomic risk assessment outputs from RULA and the Strain Index, according to kappa and gamma scores, no agreement was reported between results of these methods for upper extremities (32). In several comparative studies, different results have been reported for ergonomics risk assessment observational methods (30, 33-35).

The important point is that, although REBA and QEC are posture based methods, since QEC measured additional risk, difference in results from REBA (or being in the high risk category) is not unexpected. Hence, because of difference in the nature of occupations (type of workplace), characteristics/abilities of ergonomic risk analysis tools, and graduate students experience and knowledge/training, results of workstation postural analysis will be different. The small sample size was a limitation of this study; therefore, it is better to conduct similar studies in larger and different populations.

\section{Conclusion}

Although all ergonomic risk analysis tools have a bias, if the tools are used correctly, these biases can be recognized or considered in interpretation of total output. The results show that no agreement was found between these methods and there is no correlation between output of REBA and QEC methods and reported MSDs. Therefore, there is no possibility of interchangeable application of these methods for postural risk assessment in working stations. In ergonomic risk assessment and postural analysis, the choice of analysis tools must be based on the nature of the work, major identified ergonomic risk factors, and the results of assessment of MSDs prevalence in the workplace. An appropriate method should take into account any variables (risk factors) which may influence or impact the prevalence of MSDs. In other word, it should analyze subjects/workstations in greater detail to determine and calculate the risk level. We believe each ergonomic risk assessment method has its own usage and it is better to use these methods together to complement each other, but we do not propose the interchangeable usage of these methods.

\section{Acknowledgments}

The authors would like to extend their appreciation and gratitude to the management assistance of the aluminum plant, and Department of Health, Safety and Environment (HSE), Mr Qbakhloo for their cooperation in this survey.

Conflict of interest: None declared. 


\section{References}

1. Vanwonterghem K. Work-related musculoskeletal problems: Some ergonomic considerations. J Hum Ergol (Tokyo) 1996; 25(1):5-13.

2. Santos AC, Bredemeier M, Rosa KF, Amantéa VA, Xavier RM. Impact on the Quality of Life of an Educational Program for the Prevention of WorkRelated Musculoskeletal Disorders: a randomized controlled trial. BMC Public Health 2011; 11(1):60-8.

3. Kozak A, Schedlbauer G, Peters C, Nienhaus A. SelfReported Musculoskeletal Disorders of the Distal Upper Extremities and the Neck in German Veterinarians: A Cross-Sectional Study. PloS One 2014; 9(2):e89362.

4. Karwowski W, Marras WS. Occupational ergonomics: engineering and administrative controls (Principles and applications in engineering series). United States of America: CRC Press; 2003.

5. Ohlsson K, Attewell R, Skerfving S. Self-reported symptoms in the neck and upper limbs of female assembly workers. Impact of length of employment, work pace, and selection. Scand $\mathrm{J}$ Work Environ Health 1989; 15(1):75-80.

6. Holder NL, Clark HA, DiBlasio JM, Hughes CL, Scherpf JW, Harding L, et al. Cause, prevalence, and response to occupational musculoskeletal injuries reported by physical therapists and physical therapist assistants. Phys Ther 1999; 79(7):642-52.

7. Kilbom Å. Prevention of work-related musculoskeletal disorders in the workplace. Int J Ind Ergon 1998; 21(1):1-3.

8. Karwowski W, Marras WS. The occupational ergonomics handbook. London: CRC Press; 1998.

9. McAtamney L, Nigel Corlett E. RULA: a survey method for the investigation of work-related upper limb disorders. Appl Ergon 1993; 24(2):91-9.

10. Kemmlert K. Prevention of occupational musculoskeletal injuries. Labour Inspectorate investigation. Scand J Rehabil Med Suppl 1996; 35:1-34.

11. Yassi A. Work-related musculoskeletal disorders. Curr Opin Rheumatol 2000; 12(2):124-30.

12. Hagberg M, Morgenstern H, Kelsh M. Impact of occupations and job tasks on the prevalence of carpal tunnel syndrome. Scand J Work Environ Health 1992; 18(6):337-45.

13. Bernard BP, Putz-Anderson V, Bernard BP, Burt SE, Cole LL, Fairfield-Estill C, et.al. Musculoskeletal disorders and workplace factors: a critical review of epidemiologic evidence for work-related musculoskeletal disorders of the neck, upper extremity, and low back. National Institute for Occupational Safety and Health: Columbia Parkway Cincinnati; 1997.

14. Rwamamara R. Risk assessment and analysis of workload in an industrialized construction process. Construction Information Quarterly 2007; 9(2):80-5.

15. Kim S, Nussbaum MA, Jia B. Low back injury risks during construction with prefabricated (panelised) walls: effects of task and design factors. Ergonomics 2011;54(1):60-71.
16. Choobineh A, Tabatabaee SH, Behzadi M. Musculoskeletal problems among workers of an Iranian sugar-producing factory. Int $\mathbf{J}$ Occup Saf Ergon 2009; 15(4):419-24.

17. Janowitz I, Gillen M, Ryan G, Rempel D, Trupin L, Swig L, et al. Measuring the physical demands of work in hospital settings: Design and implementation of an ergonomics assessment. Appl Ergon 2006; 37(5):641-58.

18. Cheng AS, So PC. Development of the Chinese Version of the Quick Exposure Check (CQEC). Work 2014; 48(4):503-10.

19. Zare R, Khazraei T, Choobineh AR, Daneshmandi H, Tayefeh Rahimian J, Rajabi AH. Assessment of the Risk of Musculoskeletal Disorders using the Quick Exposure Check Technique among the Workers of a Shipbuilding Company. Sadra Medical Sciences Journal 2014; 2(4):399-406.

20. Bulduk EÖ, Bulduk S, Süren T, Ovalı F. Assessing exposure to risk factors for work-related musculoskeletal disorders using Quick Exposure Check (QEC) in taxi drivers. Int J Ind Ergon 2014; 44(6):817-20.

21. Moussavi-Najarkola SA, Mirzaei R. Assessment of musculoskeletal loads of electric factory workers by rapid entire body assessment. Health Scope 2012; 1(2):71-9.

22. Das B. Prevalence of work-related musculoskeletal disorders among the brick field workers of West Bengal, India. Arch Environ Occup Health 2014; 69(4):231-40.

23. Motamedzade M, Ashuri MR, Golmohammadi R, Mahjub H. Comparison of ergonomic risk assessment outputs from rapid entire body assessment and quick exposure check in an Engine Oil Company. J Res Health Sci 2011; 11(1):26-32.

24. Karwowski W, Marras WS. The Occupational Ergonomics Handbook. USA: CRC-Press;1998.

25. Hignett S, McAtamney L. Rapid entire body assessment (REBA). Appl Ergon 2000; 31(2):201-5.

26. Saremi M. Assessment of Musculoskeletal disorders among dentistry of Shahed University [MSc Thesis]. Tehran: Tarbiat Modares University; 2002.

27. Li G, Buckle P. A practical method for the assessment of work-related musculoskeletal risks-Quick Exposure Check (QEC). Proceedings of the Human Factors and Ergonomics Society Annual Meeting; 1998.

28. David G, Woods V, Buckle P, Stubbs D, editors. Further development of the Quick Exposure Check (QEC). In: Ergonomics in the Digital Age. Proceeding of The XVth Triennial Congress of the International Ergonomics Association; 2003 August 24-August 29; Seoul, Korea.

29. Qutubuddin SM, Hebbal SS, Kumar ACS. An ergonomic study of work related musculoskeletal disorder risks in Indian Saw Mills. Journal of Mechanical and Civil Engineering 2013; 7(5):7-13.

30. Chiasson MÈ, Imbeau D, Aubry K, Delisle A. Comparing the results of eight methods used to evaluate risk factors associated with musculoskeletal disorders. Int J Ind Ergon 2012;42(5):478-88. 
31. Qutubuddin SM, Hebbal SS, Kumar ACS. Ergonomic Risk Assessment using Postural Analysis Tools in a Bus Body Building Unit. Industrial Engineering Letters 2015; 3(8):10- 21.

32. Drinkaus P, Sesek R, Bloswick D, Bernard T, Walton $\mathrm{B}$, Joseph B, et al. Comparison of ergonomic risk assessment outputs from Rapid Upper Limb Assessment and the Strain Index for tasks in automotive assembly plants. Work 2002; 21(2):16572.

33. Serranheira F, Sousa-Uva A. Evaluación de riesgo de ETRSME TMOLCE: diversas herramientas, diversos resultados!: Qué estamos midiendo? Med Segur Trab 2008; 54(212):7-19.

34. Joseph C, Imbeau D, Nastasia I. Measurement consistency among observational job analysis methods during an intervention study. Int J Occup Saf Ergon 2011; 17(2):139-46.

35. Jones $\mathrm{T}$, Kumar S. Comparison of ergonomic risk assessment output in four sawmill jobs. Int $\mathrm{J}$ Occup Saf Ergon 2010; 16(1):105-11. 